\title{
An Exposure Appraisal of Outdoor Air Pollution on the Respiratory Well-being of a Developing City Population
}

\author{
Yahaya A. Aliyu ${ }^{1,2,}$, Joel O. Botai ${ }^{1,3}$ \\ ${ }^{1}$ Department of Geography, Geoinformatics and Meteorology, University of Pretoria, Pretoria, South Africa \\ ${ }^{2}$ Department of Geomatics, Ahmadu Bello University, Zaria, Nigeria \\ ${ }^{3}$ South African Weather Service, Erasmusrand, Pretoria, South Africa
}

\section{ARTICLE INFO}

Article History

Received 27 February 2018

Accepted 5 April 2018

Keywords

Air pollution

respiratory health

Zaria

\begin{abstract}
Zaria is the educational hub of northern Nigeria. It is a developing city with a pollution level high enough to be ranked amongst the World Health Organization's (WHO) most polluted cities. The study appraised the influence of outdoor air pollution on the respiratory well-being of a population in a limited resource environment. With the approved ethics, the techniques utilized were: portable pollutant monitors, respiratory health records, WHO AirQ+ software, and the American Thoracic Society (ATS) questionnaire. They were utilized to acquire day-time weighted outdoor pollution levels, health respiratory cases, assumed baseline incidence (BI), and exposure respiratory symptoms among selected study participants respectively. The study revealed an average respiratory illness incidence rate of 607 per 100,000 cases. Findings showed that an average of 2648 cases could have been avoided if the theoretical WHO threshold limit for the particulate matter with diameter of $<2.5 / 10$ micron $\left(\mathrm{PM}_{2.5} / \mathrm{PM}_{10}\right)$ were adhered to. Using the questionnaire survey, phlegm was identified as the predominant respiratory symptom. A regression analysis showed that the criteria pollutant $\mathrm{PM}_{2.5}$, was the most predominant cause of respiratory symptoms among interviewed respondents. The study logistics revealed that outdoor pollution is significantly associated with respiratory well-being of the study population in Zaria, Nigeria.
\end{abstract}

(C) 2018 Atlantis Press International B.V.

This is an open access article under the CC BY-NC license (http://creativecommons.org/licenses/by-nc/4.0/)

\section{INTRODUCTION}

Clean air is extremely essential for human well-being [1]. Ambient air quality remains a major concern in developing cities with limited pollution monitoring capabilities [2]. The spatial and temporal classification of city-scale ambient air quality is vital from any respiratory epidemiological standpoint [3]. Estimates have put respiratory infections as the cause of nearly $20 \%$ of mortality in children younger than 5 years, with a sizeable portion of the dilemma experienced by populations in Africa and Asia [4]. Managing air pollution can be very complex, especially as it revolves around the intricacy of emission sources, implementation strategy concerns, and scarce means for regulating and pursuance [5]. These difficulties, combined with the hurried demand for technological advancement in many countries, have resulted in global concern on possible vulnerability from air pollution $[6,7]$.

Anthropogenic emissions are the largest contributors of urban outdoor air pollution as they emit various kinds of petrochemical gases into the atmosphere [8-10]. The atmospheric air quality plays a crucial role in population health as its pollution is projected to be responsible for $3.2 \%$ of the worldwide burden of diseases [11]. Other than conventional respiratory illnesses, poor air quality is

*Corresponding author. Email: u15221408@tuks.co.za also reported to be linked with nonrespiratory health conditions such as, diabetes [12], stroke [13], and infertility [14].

Strategies are being identified for reducing population exposure to air pollution. They include: restricting air pollution emitters, technological upgrade on emitters to cut or eradicate emissions, and creating health risks alertness of pollution exposure to population [15-17]. The idea of restriction or technological upgrades of air pollution sources can be strenuous to enforce or probably not in line with the paradigms of the state, such as restrictions that may end up minimizing economic output [18]. Providing health hazard awareness on air pollution is a concrete first step for policies that find it tasking to revolutionize their present emission status and if executed properly, it will provide health benefits [19].

In Nigeria, atmospheric pollution and its burden of respiratory diseases is still a serious menace in many of its metropolitan cities. This is mainly due to expended vehicles, general use of the single-engine motorcycles for shuttling commuters, traffic congestions, and the natural north-easterly harmattan which all combine to generate high levels of localized air pollution that can affect population health [20]. With Nigerian cities now beginning to rank among the top most polluted in the world [11], it is worth noting that researches are identifying increased occurrence of respiratory disease symptoms in individuals exposed to this pollution [21-23]. 
This study is a step in confronting public concerns as it aims to evaluate the influence of outdoor air pollution on interim respiratory well-being within a limited resource environment. To achieve this, it is necessary to (1) first assess the present air pollution levels within the study population; (2) determine the theoretical attributable risk proportion using the available respiratory health outcome information and the measured exposure level; and (3) establish whether outdoor air pollutant exposure is significantly associated with the respiratory symptoms within the study population. For reliable theoretical influence, pollution epidemiology studies require pollution and health outcome data covering a reasonable time-frame. This study hopes to provide a scientific basis for air pollution regulation in a local metropolis of Nigeria.

\section{MATERIALS AND METHODS}

\subsection{Study Area}

This study was conducted in Zaria metropolitan area, northern Nigeria (Figure 1). Zaria metropolis consists of two local government districts (Zaria and Sabon Gari) and occupies an area of $\sim 296.036 \mathrm{~km}^{2}$. It is the educational hub of northern Nigeria. The topography is mainly flat with a mean height of $670 \mathrm{~m}$ above mean sea level (MSL). The climate comprises of the dry (OctoberMay) and wet (June-September) seasons. The lowest temperature is $14.1^{\circ} \mathrm{C}$ and maximum average is $35.2^{\circ} \mathrm{C}$ during the harmattan (January) and heat (April) seasons. The population in 2016 was estimated to be 938,521 using the 2006 population census and a $3 \%$ growth rate [24]. The western areas are sparsely vegetated around the Kufena Hills. The main water body in the study area is the River Kubanni.

\subsection{Ethics}

Research protocols were endorsed by the Kaduna State Ministry of Health Research Ethics Committee (MOH/ADM/744/ VOL.1/448); Ahmadu Bello University Teaching Hospital Health Research Ethics Committee (ABUTH/HREC/CL/05) within the study area and the Faculty of Natural and Agricultural Sciences Ethical Committee at the University of Pretoria, South Africa (EC170124-092).

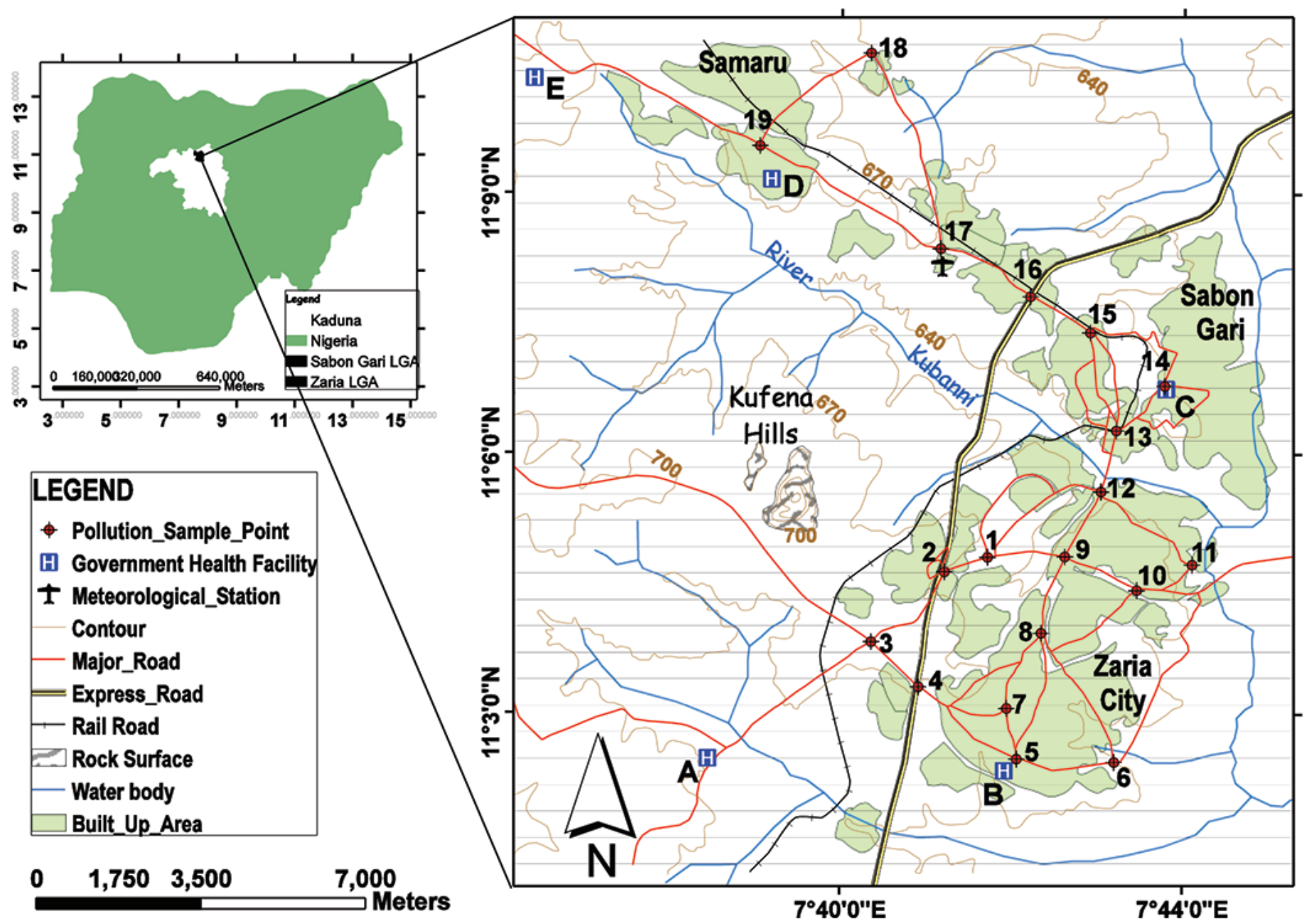

Figure 1 The study area showing the distribution of pollution sample sites and government health facilities from which respiratory health records were obtained 


\subsection{Data Collection}

To appraise the influence of outdoor air pollution on respiratory well-being within the study area, four categories of datasets were obtained. They are described as follows.

\subsubsection{Outdoor pollution data}

With the design of numerous handy cost effective devices for monitoring airborne contaminants [25-27], this study utilized portable air quality monitors to collect pollution data. The sample monitors were: The MSA Altair 5× and the CW-HAT200 particulate counter are manufactured by the Mine Safety Appliances Company, Pennsylvania, USA and the Shenzhen Chinaway Environmental Technologies Co. Ltd, Guangdong, China respectively (Figures 2A and 2B). The MSA Altair collects criteria pollutants: carbon monoxide (CO) and sulfur dioxide $\left(\mathrm{SO}_{2}\right)$, measured in parts per million (ppm) whereas the CW-HAT200 collects particulate matter $\mathrm{PM}_{2.5}$ and $\mathrm{PM}_{10}$ in micrograms per cubic meter $\left(\mu \mathrm{g} / \mathrm{m}^{-3}\right)$. The portable pollutant devices were validated $(R>$ $0.96)$ before commencement of proper sampling. The World Health Organization (WHO) filter sampling procedure, described in Efe and Efe [28], was adopted to validate the portable devices used in this study. A total of 19 sample sites distributed across the study area, were utilized to routinely observe air pollution concentrations, 3-epochs daily $[29,30]$. The duration of the outdoor sampling was from December 1 , 2015 to November 30, 2016. The sites were situated along the major road intersections. A total of 16 sites were positioned within dense population activities which cut across the residential and commercial settlements, whereas the remaining three control sites were positioned strategically at the outskirts of the city with minimal population activity. The control sites were embraced to aid in the result comparison.

\subsubsection{Attributable risk data}

The health records of respiratory illnesses utilized in this study were restricted to the five major government-owned health facilities in the study area. This is because, they are the most medically equipped thus most likely to handle referral cases. They are also cost-effective for all patients to access medical treatment. The facilities are: National Tuberculosis and Leprosy Training Centre, Hajiya Gambo Sawaba General Hospital, Major Ibrahim A. Abdullahi Memorial Hospital,
Ahmadu Bello University Medical Centre, and Ahmadu Bello University Teaching Hospital (Figure 1A-E). The data obtained comprised of reported cases from the health facility records, for varying age brackets and death occurrences for case fatality rate (CFR) computations. The obtained data were used to determine the attributable risk proportion using the AirQ+ software designed by the World Health Organization (WHO), Europe regional office.

To ascertain the theoretical attributable risk proportion (AP) of respiratory illnesses on the Zaria population, we adopted the input files embedded into the WHO air quality AirQ+ software. The inputs adopted include peer-reviewed relative risk (RR) estimates, mathematical formulae, and WHO stipulated limits. The WHO encourages the use and dissemination of information using the software. Several studies have corroborated the use of the software [31-34]. The validated AirQ+ software quantifies possible respiratory health effects resulting from exposure to pollutant within any study area. This is achieved by computing the ratio of traceable health outcomes resulting from exposure to atmospheric pollutant(s), for a defined population. It hypothesizes the relationship between exposure and health consequence, with no significant discountenance. The assumed AP can be derived using the formulae (1) [35].

$$
\mathrm{AP}=\frac{\sum\{[\mathrm{RR}(s)-1] \times p(s)\}}{\sum\{\mathrm{RR}(s) \times p(s)\}}
$$

$\mathrm{RR}(s)$ is the relative risk for the health outcome difference that can be calculated using Eq. (2); $p(s)$ is the fraction of the population all in exposure class $s$, depending on the varying level of exposure within the field of study.

$$
\mathrm{RR}(s)=\frac{(C-T)}{(10 \times(\mathrm{RR}-1)+1)}
$$

$C$ is pollutant concentration in air, $T$ is the WHO stipulated limit for detected pollutant; RR is the relative risk derived from the exposure-response function for selected health outcomes generated from local epidemiological studies.

To determine the rate and the estimated number of cases attributable to the pollution exposure, Eqs. (3) and (4) were utilized, taking into consideration that the theoretical baseline frequency of endpoint (incidence) and population size are known, respectively [33].
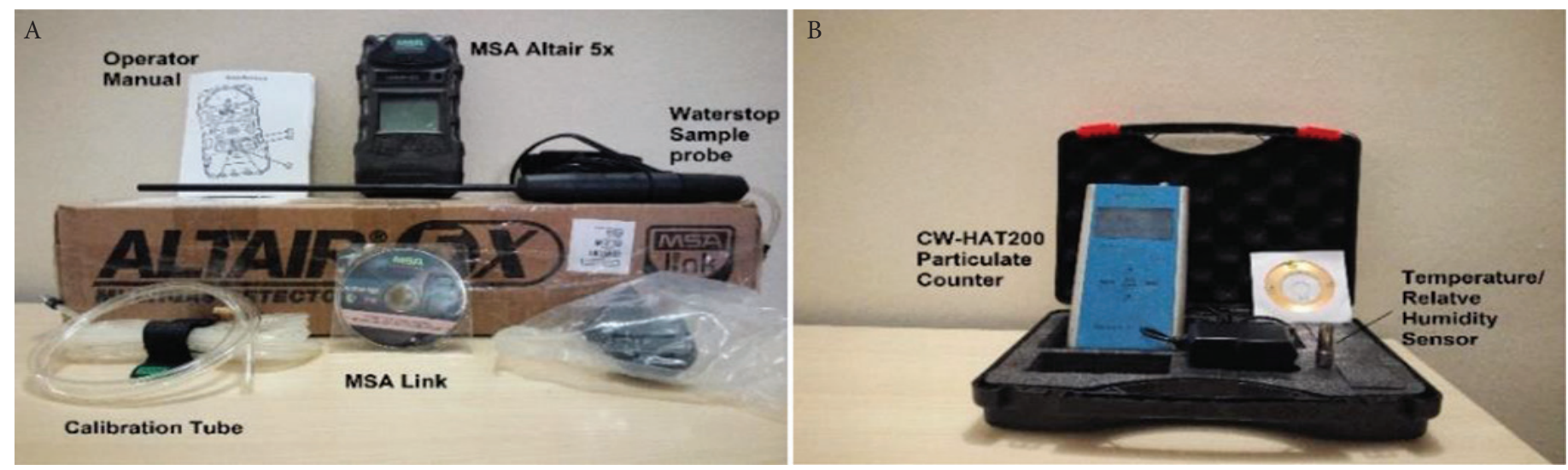

Figure 2 Portable air pollutant detectors (MSA Altair 5×/Chinaway CW-HAT200) 
A baseline incidence is a theoretical threshold derived using mathematical procedures, to determine if an epidemic incidence is in excess [36].

$$
\mathrm{IE}=I \times \mathrm{AP}
$$

IE is the rate of the health outcome related to the exposure, $I$ is the baseline frequency of the health endpoint in the population.

$$
\mathrm{NE}=\mathrm{IE} \times N
$$

$\mathrm{NE}$ is the number of cases attributed to the exposure, and $N$ refers to the size of the investigated population.

\subsubsection{Questionnaire survey data}

As a predictive indicator to analyse on-the-spot respiratory well-being resulting from outdoor pollution exposure, a respiratory indicator-based questionnaire was utilized to investigate respiratory symptoms from respondents. The American Thoracic Society Division of Lung Disease questionnaire (ATS-DLD-78A) [37] is a universally accepted process for detecting respiratory warning signs in a population. The design comprises questions related to recurrent respiratory indicators such as cough, phlegm, wheeze, and breathlessness. The questionnaire has been utilized by various studies [38-41], to achieve their objectives. In our study, we applied a modified version of the questionnaire for adults, to trace the manifestation of respiratory symptoms. It comprises questions pertaining to the occurrence of cough/ phlegm for the most part of $\geq 3$ consecutive months within a year; wheeze (noisy breath resulting in breathing difficulty on most days or only during the cold season); breathlessness Grade I, (rapid breathing as a result of hastening on a level or pacing up a slight hill) and Grade II (not being able to walk at the same pace with one's age class on a level or pausing for breath when strolling at own pace on a level). The account of past ailments (described as bronchitis, pneumonia, asthma, emphysema, hay fever confirmed by a doctor) and hereditary likelihoods (described as any of the biological parent who had any chronic lung condition such as chronic bronchitis, asthma, or lung cancer, confirmed by a doctor). We restricted the questionnaire survey to participants that were stationed within 30 -m radius of sample sites, for at least 6 hours a day, for the past year (which coincided with our pollution sampling duration). We ensured that their ages were $\geq 20$ years. With this criteria, we could confirm that such participants were mature enough and had been exposed to the recorded concentration levels of pollutants, for a considerable amount of our sample time. The sample size of participants was determined based on the minimum population sample size for research activities [42]. The questionnaire was drafted in the English language and if necessary translated to the Hausa language. The participants had paper-assisted interviews which was controlled for prolonged/already existing respiratory illnesses and likely hereditary symptoms. During the administration process, the investigator ensured that the respondents comfortably and accurately understood the value of all questions, most especially respiratory symptoms, such as phlegm and wheeze. Participants gave verbal and written informed consent. The participants were restricted to non-smoking individuals situated at the selected sample sites, so that the results are not skewed as a result of their personal habits.

\subsubsection{Socio-economic influence data}

A remote sensing Landsat data were employed to ascertain if socio-economic factors contributed to reports of respiratory well-being within the study period. Landsat data were adopted because it is an independent data that can be freely accessed from the United States Geological Survey (USGS). For our study site, the Landsat 8 at Path/Row 189/52, was acquired from the USGS website (https://earthexplorer.usgs.gov/) for the study period (December 1, 2015-November 30, 2016). To improve accuracy, the image data were restricted to satellite image tiles with $<10 \%$ cloud cover. Only 10 image files fulfilled the specified criteria for the entire study period. The socio-economic factor can be interpreted in the Landsat data as land surface temperature (LST) and normalized difference vegetation index (NDVI). The derivation techniques for LST and NDVI are described in Sobrino et al. [43] and $\mathrm{Xu}$ and Guo [44].

\subsection{Data Analysis}

The day-time weighted average for observed criteria pollutants was computed for the 1-year running. The spatial data (easting, northings, and elevation) of the sampling points and their individually observed pollution levels were analysed to determine for skewness of sampling position. The spatial distribution of reported respiratory symptoms were analysed for homogeneity of variance using the Levene's test. The respiratory health data with variables (age group, sex, and resulting mortality) were subjected to statistical logistics, to determine their association with outdoor pollution exposure through a likelihood ratio test. To determine population exposed response, the ATS questionnaire responses were coded and analysed for all responded respiratory outcomes. The empirical analysis did correct for possible priors and hereditary respiratory traits. A reliability test was also conducted on the ATS questionnaire. All statistical computations were executed in the Microsoft Windows environment using the Microsoft Excel, SPSS 19 software from IBM and Matlab R2014b from MathWorks.

\section{RESULTS}

The day-time seasonal statistics for $\mathrm{CO}(\mathrm{ppm}), \mathrm{SO}_{2}(\mathrm{ppm}), \mathrm{PM}_{2.5}$ $\left(\mu \mathrm{g} / \mathrm{m}^{-3}\right)$, and $\mathrm{PM}_{10}\left(\mu \mathrm{g} / \mathrm{m}^{-3}\right)$ is averaged over the 19 sample stations in Zaria, Nigeria during the period December 2015November 2016 (Figure 3). The 1-year day-time weighted average concentration of criteria pollutants revealed values of $29.22 \mathrm{ppm}$ for $\mathrm{CO}, 0.32 \mathrm{ppm}$ for $\mathrm{SO}_{2}, 219.73 \mu \mathrm{g} / \mathrm{m}^{-3}$ for $\mathrm{PM}_{2.5}$, and $451.89 \mu \mathrm{g} / \mathrm{m}^{-3}$ for $\mathrm{PM}_{10}$.

From the health records obtained, an aggregate of 31,042 respiratory related illnesses were reported in the five major government owned health facilities in Zaria metropolis from January 2011 to December 2016 (Table 1). A total of 461 respiratory-related casualties were recorded. All the years of interest (2011-2016) did record respiratoryrelated deaths, with 2013 having the peak (112 deaths). On average, the CFR was $1.67 \%$, over the study period under investigation.

To determine if the outdoor pollution level significantly contributed to exposed population respiratory symptoms, a total of 396 responses were obtained. We ensured that each of the 19 sample 


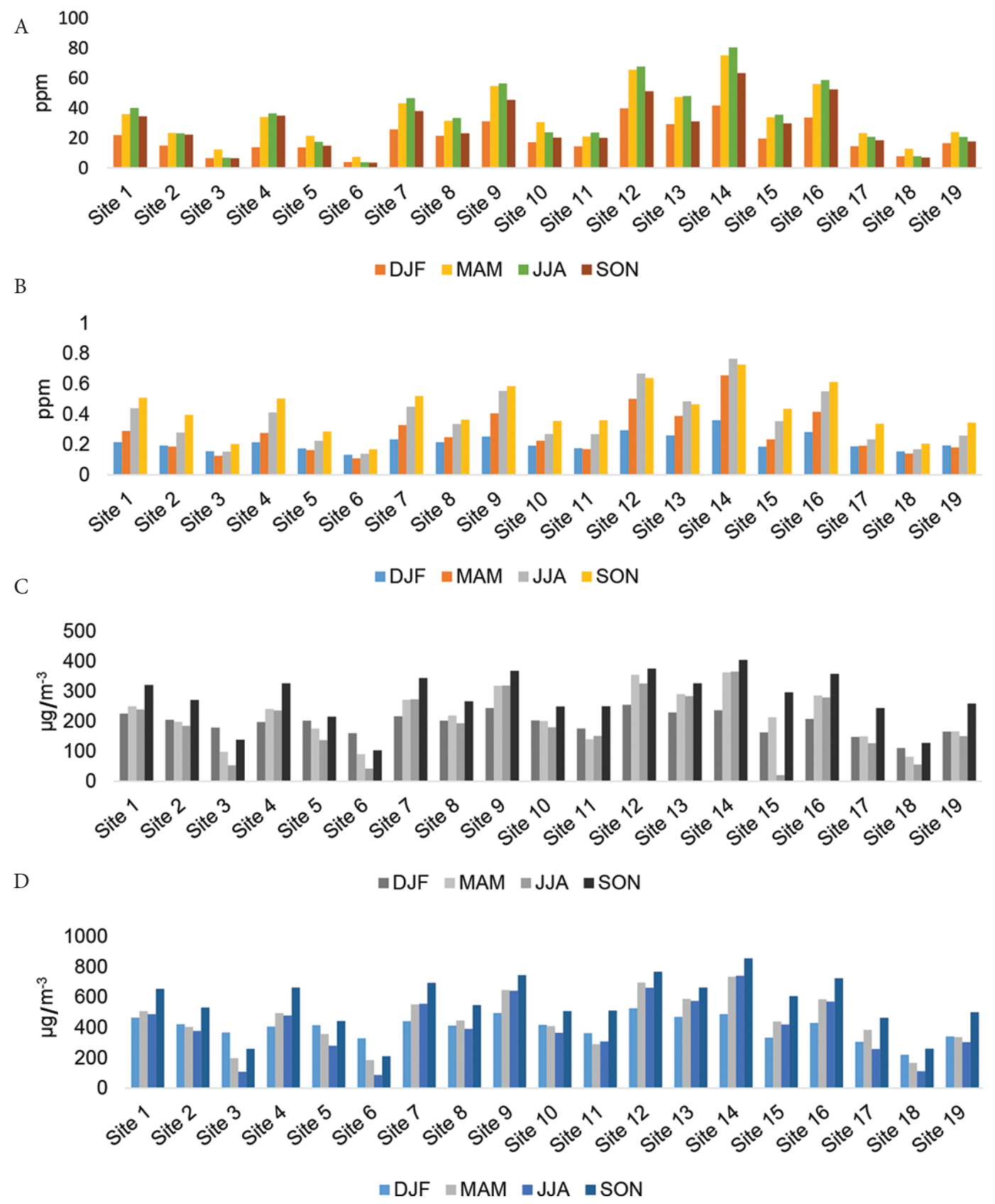

Figure 3 Histogram of seasonal day-time pollutant concentrations across the 19 sampling sites (A) CO; (B) $\mathrm{SO}_{2} ;(\mathrm{C}) \mathrm{PM}_{2.5} ;(\mathrm{D}) \mathrm{PM}_{10}$. (Sites 3,6 , and 18 are control sites). DJF, December-January-February; MAM, March-April-May; JJA, June-July-August; SON, September-October-November

Table 1 Recorded respiratory cases and related deaths in Zaria metropolis, 2011-2016

\begin{tabular}{|c|c|c|c|c|c|c|c|c|c|c|}
\hline \multirow{2}{*}{ Year } & \multirow{2}{*}{ Total cases } & \multirow{2}{*}{ Case $/ 100,000^{*}$} & \multicolumn{6}{|c|}{ Case (\%) } & \multirow{2}{*}{ Death } & \multirow{2}{*}{ CFR } \\
\hline & & & $0-14$ years & $15-29$ years & $30-44$ years & $>45$ years & Male & Female & & \\
\hline 2011 & 4992 & 635 & 2065 (41.4) & $1650(33.0)$ & $784(15.7)$ & 493 (9.9) & $2746(55.0)$ & $2246(45.0)$ & 78 & 1.6 \\
\hline 2012 & 5996 & 741 & $1498(25.0)$ & $2757(46.0)$ & $1126(18.8)$ & $615(10.2)$ & $3525(58.8)$ & $2471(41.2)$ & 95 & 1.6 \\
\hline 2013 & 3003 & 360 & $815(27.1)$ & $1361(45.3)$ & $482(16.1)$ & 345 (11.5) & $1694(56.4)$ & $1309(43.6)$ & 45 & 1.5 \\
\hline 2014 & 3297 & 383 & $1056(32.0)$ & $1302(39.5)$ & $554(16.8)$ & 385 (11.7) & 1909 (57.9) & $1388(42.1)$ & 112 & 3.4 \\
\hline 2015 & 5428 & 614 & $1757(32.4)$ & $2392(44.1)$ & $826(15.2)$ & $453(8.3)$ & $3136(57.8)$ & $2292(42.2)$ & 66 & 1.2 \\
\hline 2016 & 8326 & 914 & $2818(33.8)$ & $3522(42.3)$ & $1313(15.8)$ & $673(8.1)$ & $4993(60.0)$ & $3333(40.0)$ & 65 & 0.8 \\
\hline
\end{tabular}

"Derived from the yearly population estimates; CFR, case fatality rates. 
stations had at least 20 responses, i.e., participants situated at exposed stations were tagged as exposed whereas participants responding from control stations were tagged as control. There were $352(88.9 \%)$ males and $44(11.1 \%)$ females as participants. The internal-consistency reliability (Cronbach $\alpha$ ) of the ATS interview was within acceptable limits $(\alpha>0.70)$. Predominant respiratory symptom was phlegm (97.2\%), followed by chest cough $(80.8 \%)$, dyspnoea (55.6\%), chest cough plus phlegm (54.8\%), and wheeze (49.8\%). Pneumonia (14.1\%) was the major medically-diagnosed past respiratory illness. This can be attributed to the annual natural windy 'harmattan' period that is characterized with dusty conditions and low temperatures. Table 2 shows the descriptive statistics of respiratory symptoms among interviewed respondents. The interviewed responses were coded for further analysis.

\section{DISCUSSION}

\subsection{Outdoor Air Quality}

The skewness analysis $(p<0.184)$ revealed that the recorded pollution levels were normally distributed across the 19 study sites. The pollution level of the observed criteria-pollutants were lowest

Table 2 Descriptive statistics of respiratory symptoms among interviewed respondents in the study area

\begin{tabular}{|c|c|c|c|}
\hline Case characteristics & Male $(n)$ & Female $(n)$ & Total, $n(\%)$ \\
\hline Study population, $n(\%)$ & $352(88.9)$ & $44(11.1)$ & 396 \\
\hline \multicolumn{4}{|l|}{ Age (years) } \\
\hline $20-29$ & 38 & 15 & $53(13.4)$ \\
\hline $30-39$ & 133 & 10 & $143(36.1)$ \\
\hline $40-49$ & 149 & 9 & $158(39.9)$ \\
\hline$\geq 50$ & 32 & 10 & $42(10.6)$ \\
\hline \multicolumn{4}{|l|}{ Education } \\
\hline Primary & 33 & 2 & $35(8.9)$ \\
\hline Secondary & 169 & 16 & $185(46.7)$ \\
\hline Tertiary & 150 & 26 & $176(44.4)$ \\
\hline \multicolumn{4}{|l|}{ Respiratory conditions } \\
\hline Chest cough & 289 & 31 & $320(80.8)$ \\
\hline Phlegm & 344 & 41 & $385(97.2)$ \\
\hline Cough \& phlegm & 200 & 17 & $217(54.8)$ \\
\hline Wheeze & 175 & 22 & $197(49.8)$ \\
\hline Breathlessness & 192 & 28 & $220(55.6)$ \\
\hline \multicolumn{4}{|l|}{ Past illnesses } \\
\hline Lung trouble before $16 y$ & 18 & 3 & $21(8.3)$ \\
\hline Bronchitis attack & 14 & 3 & $17(4.3)$ \\
\hline Pneumonia attack & 47 & 9 & $56(14.1)$ \\
\hline Asthma attack & 15 & 4 & $19(4.8)$ \\
\hline Emphysema & 31 & 1 & $32(8.1)$ \\
\hline Hay fever & 2 & - & $2(0.5)$ \\
\hline Chest illness & 5 & 1 & $6(1.5)$ \\
\hline Chest operation & 3 & - & $3(0.8)$ \\
\hline Chest injury & 12 & 2 & $14(3.5)$ \\
\hline Heart trouble & 5 & 3 & $8(2.0)$ \\
\hline High blood pressure & 23 & 5 & $28(7.1)$ \\
\hline \multicolumn{4}{|l|}{ Hereditary probability } \\
\hline Father & 36 & 3 & $39(9.9)$ \\
\hline Mother & 60 & 10 & $70(17.7)$ \\
\hline
\end{tabular}

during the December-January-February season, this can be attributed to the windy harmattan (cold season) in the study area. The windy harmattan season has the tendency to quickly disperse pollution emissions. In addition, outdoor activities are limited due to low ambient temperatures especially during morning and evening periods. The weighted average concentration level of $\mathrm{CO}$ measured were above the WHO/FEPA (Nigeria) stipulated limit (Table 3) in 15 of the 19 sample sites; $\mathrm{SO}_{2}$ and $\mathrm{PM}_{10}$ levels were above the WHO/FEPA limit in all the sites; $\mathrm{PM}_{2.5}$ were above the WHO limit in all the sample sites (Nigeria's Federal Environmental Protection Agency (FEPA) has no specified limit for $\mathrm{PM}_{2.5}$ ); $\mathrm{PM}_{10}$ was above the WHO/FEPA limit in all the sites. Considering the global ambient air pollution update in the WHO 2016 results, the weighted average concentration level of recorded $\mathrm{PM}_{2.5}$ and $\mathrm{PM}_{10}$ firmly puts Zaria among the top five polluted cities of the world.

\subsection{Attributable Health Risk}

A Levene's test revealed that the spatial distribution of reported respiratory symptoms in Zaria metropolis was heterogeneous ( $p=$ 0.050 ). In Table 2 , the health records indicate the most respiratory cases were notified in Ahmadu Bello University Medical Center (D) [3856.83; 95\% confidence interval (CI): 2199.9-5513.8]. This is attributed to the fact that it is the only major health facility within a $4-\mathrm{km}$ radius of Zaria's Samaru axis. The least notified cases were reported at the Ahmadu Bello University Teaching Hospital (E) (34.5; 95\% CI: 4.2-64.9). This may be attributed to its location, which is at the outskirts of the metropolis. Using the population estimates, the respiratory illness incidence rate was highest in 2016 (914/100,000). Table 2 highlights the trend of reported respiratoryrelated complaints obtained from the major health facilities. Respiratory illnesses were reported for age ranging from infancy ( $<1$ year) to elderly (76 years). The physically active group of 15-44 years, which accounts for $58.21 \%(18,069)$ of all notified cases, were most at risk over the study period. Their case was remarkably high in 2016 with $58.07 \%$ (4835) of cases. The age group 0-14 years ranked second, accounting for $32.24 \%(10,009)$ of all notified cases and $33.85 \%$ (2818) in 2016. The age group of 45 years and older were the least affected by respiratory illnesses, accounting for $9.55 \%$ (2964) of total notified cases and a major report of $8.08 \%$ (673) in 2016. From 2011 to 2016, respiratory related illnesses afflicted more males $58.0 \%(18,003)$ compared with females $42.0 \%(13,039)$. This trend was harmonious all through the study period $\left(r^{2}=0.994\right.$; $p<0.01)$. With available pollution data for the year 2016, the WHO AirQ+ software was utilized to compute the theoretical attributable risk proportion for the study area in 2016.

To determine the theoretical AP for 2016, the total of 8326 cases of respiratory diseases, day-time weighted running average of $\mathrm{PM}_{2.5}$

Table 3 Threshold of selected air pollutants, modified after(FEPA, 1999; [45])

\begin{tabular}{lcccc}
\hline & \multicolumn{4}{c}{ Pollutants } \\
\cline { 2 - 5 } Stipulated limits & $\mathbf{C O}(\mathbf{p p m})$ & $\begin{array}{c}\mathbf{P M}_{2.5} \\
\left(\mu \mathrm{g} / \mathbf{m}^{-3}\right)\end{array}$ & $\begin{array}{c}\mathbf{P M}_{10} \\
\left(\mu \mathrm{g} / \mathbf{m}^{-3}\right)\end{array}$ & $\mathbf{S O}_{2}(\mathbf{p p m})$ \\
\hline FEPA & 20 & - & 150 & 0.1 \\
WHO & 9 & 25 & 50 & 0.01 \\
\hline
\end{tabular}

WHO, World Health Organization; FEPA, Federal Environmental Protection Agency. 
and $\mathrm{PM}_{10}$ are 219.73 and $451.89 \mu \mathrm{g} / \mathrm{m}^{-3}$, respectively, and all other parameters were inserted into the AirQ+ software. The model report revealed that $32.62 \%$ and $29.12 \%$ of notified respiratory cases can be attributed to pollutants $\mathrm{PM}_{2.5}$ and $\mathrm{PM}_{10}$, respectively, having exceeded the stipulated threshold. In Table 3, we can see that for every $10 \mu \mathrm{g} / \mathrm{m}^{-3}$ increase in $\mathrm{PM}_{25}$ pollutant concentration, the corresponding amount of $\mathrm{RR}$ for the hospital accessed respiratory illnesses was $1.484 \%$ as well as $1.411 \%$ for every $20 \mu \mathrm{g} / \mathrm{m}^{-3}$ increase in $\mathrm{PM}_{10}$. An average of $31.8 \%$ (2648 cases) could have been avoided if the WHO guideline for $\mathrm{PM}_{2.5}$ and $\mathrm{PM}_{10}$ had been respected in 2016 . However, the theoretical baseline incidence per 100,000 for shortterm effects of population exposed to $\mathrm{PM}_{2.5}$ and $\mathrm{PM}_{10}$ (298.10 and 271.27) are minimal compared with the WHO guideline of 1260 for the land mass and total estimated population of Zaria.

The adopted relative risk (RR) value for concerned air pollutants (Table 4) are based on multiple analysis of peer-reviewed findings conducted in Asia, North America, and Western Europe [32,33,46]. Even though our study understood that the adoption of the theoretical $\mathrm{RR}$ obtained from researches conducted outside our region may alter predictions of the model, we felt that there is the need to most importantly drive the step in providing valuable evidence on the effects of air pollution for Nigeria's policy-makers. We were also optimistic that our findings will assist the WHO AirQ+ software developers to further moderate any prediction error. Based on the available datasets, we utilized the theoretical WHO AirQ+ software to assess the interim effects of $\mathrm{PM}_{2.5}$ and $\mathrm{PM}_{10}$.

\subsection{Pollution Exposure Response}

To determine if the outdoor air pollutants measured within the study area can contribute to the respiratory condition of present population, we analysed the relationship between each measured criteria pollutant against the individual respiratory response interviewed. Table 5 shows association between the presence of respiratory symptoms from interviewed respondents and observed criteria pollutant level.

Additionally, we determined the contribution of measured pollution level to the general respiratory outcome of the interviewed population. The interviewed respondent outcomes were controlled for past illnesses and possible family hereditary influence using the formulae (5).

$$
\mathrm{PER}=\left[\sum_{i=1}^{n} S_{i}-\left(\sum_{i=1}^{n} P_{i}+\sum H\right)\right]
$$

PER is the pollution exposure response; $S_{i}$ is responses from respondents for the varying symptoms (chest cough, phlegm, cough plus phlegm, wheeze, and breathlessness); $P_{i}$ is responses with regards past illnesses (lung disease before 16 years of age, bronchitis, asthma, chest injuries/operation, high blood pressure) and $H$ is responses with regards a possible inheritance of symptoms from biological parents.

From Figure 4 we see that the $\mathrm{PM}_{2.5}$ is the predominant cause of interviewed respiratory symptoms $(r=0.93)$. This result supported the WHO AirQ+ software findings (Table 3) and also literature $[33,47]$. In addition, $\mathrm{SO}_{2}$ ranked second after $\mathrm{PM}_{2.5}$, which is in agreement with Ren et al. [48]. Their study reported $\mathrm{SO}_{2}$ as their major cause of respiratory related illnesses, however $\mathrm{PM}_{2.5}$ was not investigated.

To certify that the exposure to outdoor air pollutants in this population was the major contributor of the measured respiratory symptoms, we analysed the level of significance of the socioeconomic factor on respiratory well-being. Using independent remote sensing approach, we derived the LST and the NDVI from Landsat 8 data, in the ArcGIS 10.2.1 software. The LST and NDVI values over the 19 sample points were extracted, collocated, and correlated with ATS questionnaire responses across the sample sites. The analysis show the socio-economic factors, LST $(r=$ $0.76)$ and NDVI $(r=0.69)$. The results were not as significant as

Table 4 WHO theoretical values of relative risks (RR) implemented in AirQ+ corresponding to hospital admission/access for respiratory diseases and estimated RR in percentage and excess of number cases in 2016 resulting from short-term exposure to $\mathrm{PM}_{2.5} / \mathrm{PM}_{10}$ above the $10 / 20 \mu \mathrm{g} / \mathrm{m}^{-3}$ limits, respectively

\begin{tabular}{|c|c|c|c|c|c|c|}
\hline Pollutant & \multicolumn{2}{|c|}{ WHO default values } & \multicolumn{4}{|c|}{ Theoretical outcome } \\
\hline $\mathrm{PM}_{2.5}$ & 10 & $1.019(0.9982-1.0402)$ & 219.73 & $1.4840(0.9629-2.2856)$ & 2798 & 298.10 \\
\hline $\mathrm{PM}_{10}^{2.5}$ & 20 & $1.008(1.0048-1.0112)$ & 451.89 & $1.4108(1.235-1.6177)$ & 2498 & 271.27 \\
\hline
\end{tabular}

*The $\mathrm{PM}_{2.5}$ and $\mathrm{PM}_{10}$ threshold limit prescribed by the WHO for theoretical baseline incidence per 100,000 is 1260; CI, confidence interval; RR, relative risks; WHO, World Health Organization.

Table 5 Relationship between individual respiratory symptoms from respondents and each observed pollutants level

\begin{tabular}{|c|c|c|c|c|c|c|c|c|c|c|}
\hline & \multicolumn{2}{|c|}{ Cough } & \multicolumn{2}{|c|}{ Phlegm } & \multicolumn{2}{|c|}{ Cough and phlegm } & \multicolumn{2}{|c|}{ Wheeze } & \multicolumn{2}{|c|}{ Breathlessness } \\
\hline & $R$ & RMSE & $R$ & RMSE & $R$ & RMSE & $R$ & RMSE & $R$ & RMSE \\
\hline $\mathrm{CO}$ & 0.90 & 29.61 & 0.86 & 33.63 & 0.79 & 10.68 & 0.80 & 15.72 & 0.82 & 13.71 \\
\hline $\mathrm{SO}_{2}$ & 0.91 & 28.44 & 0.87 & 33.07 & 0.81 & 10.17 & 0.80 & 15.61 & 0.78 & 14.86 \\
\hline $\mathrm{PM}_{2.5}^{2}$ & 0.89 & 31.17 & 0.87 & 32.95 & 0.90 & 7.60 & 0.80 & 15.71 & 0.76 & 15.36 \\
\hline $\mathrm{PM}_{10}^{2.3}$ & 0.88 & 32.88 & 0.83 & 37.04 & 0.79 & 10.45 & 0.71 & 18.63 & 0.72 & 16.54 \\
\hline
\end{tabular}

Shaded cell highlights the possible association of pollution exposure and respiratory condition; $R$, correlation coefficient; RMSE, root mean square error. 
A

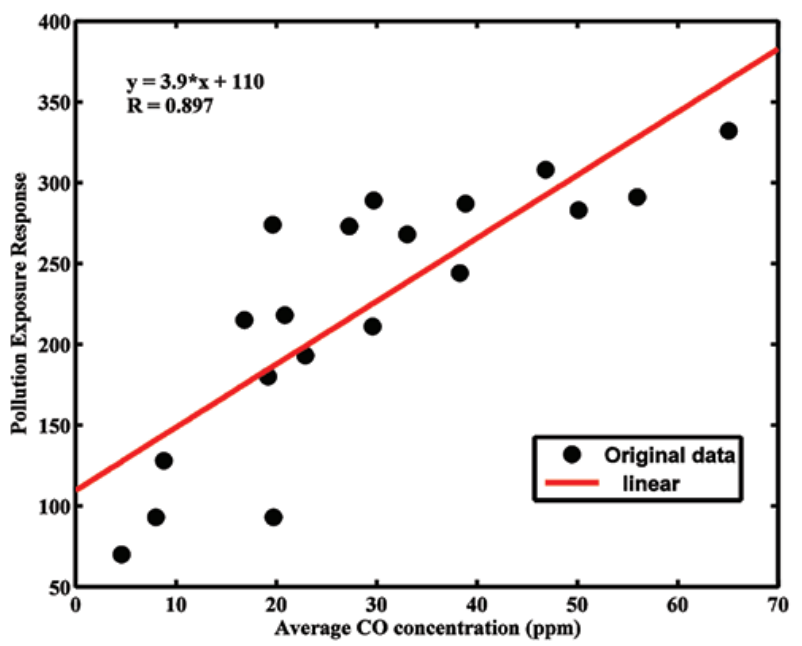

C

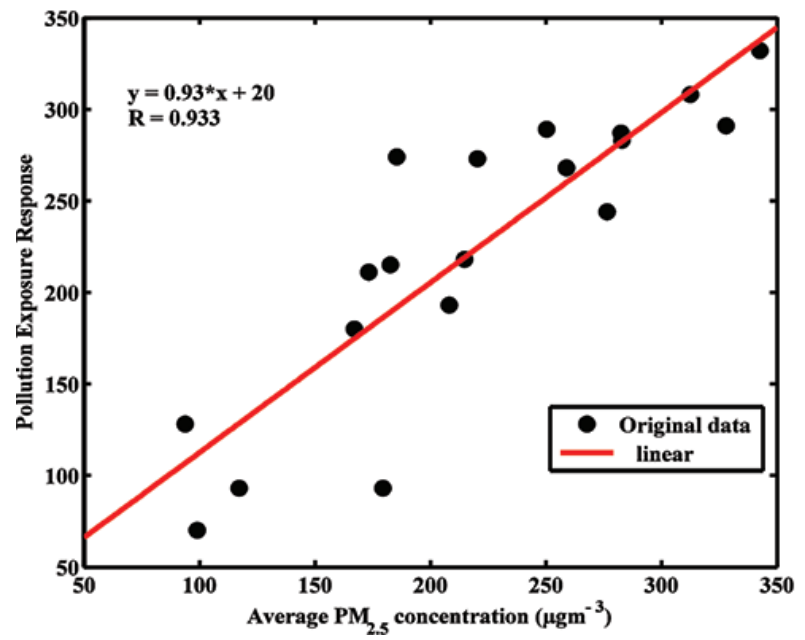

B

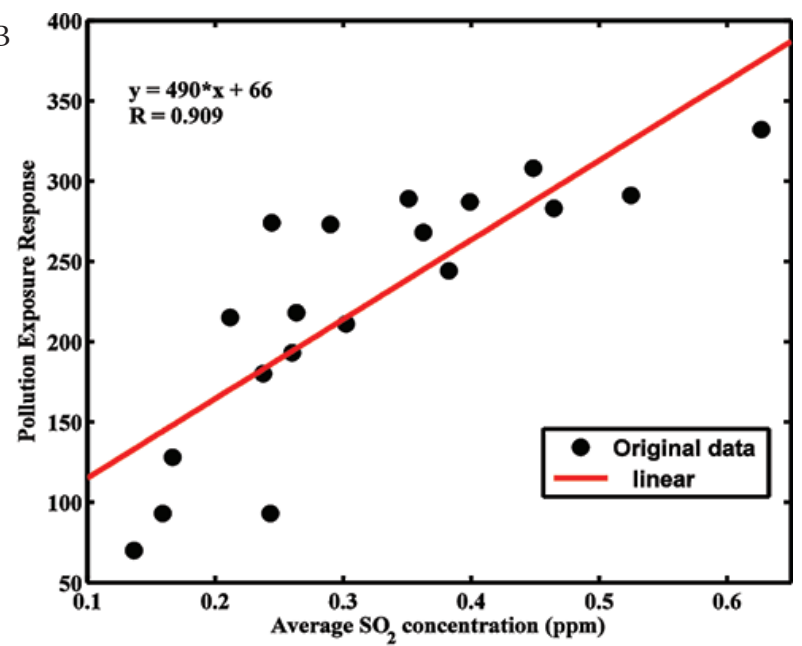

$\mathrm{D}$

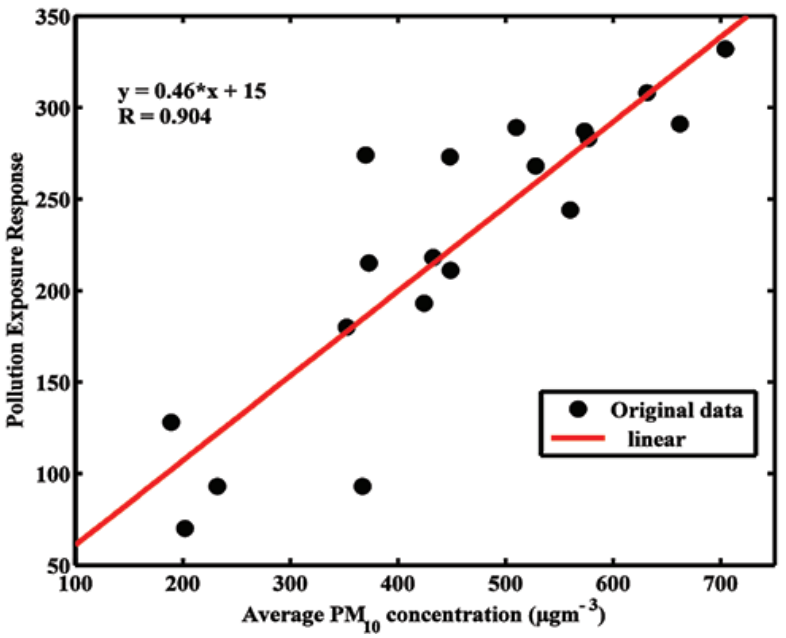

Figure 4 Scatter plot showing strong positive relationship between criteria pollutants (A) CO; (B) $\mathrm{SO}_{2}$; (C) $\mathrm{PM}_{2.5}$; and (D) $\mathrm{PM}_{10}$ respectively) against at-risk population respondents from the sample sites

the measured pollutants level for the respondent respiratory outcome in Figure $4(r \geq 0.90)$. Note that the Landsat data were validated ( $r=0.94)$ using the extracted LST and collocating ground temperature data obtained from the Nigerian Meteorological Agency station within the study area.

The study utilized portable pollutant sensors, ATS-respiratory questionnaire, and the WHO AirQ+ software model to evaluate the contributory effects of outdoor air pollution to respiratory outcomes in a highly polluted area. The study provides an encyclopaedic picture of outdoor air pollution exposure and possible ramifications to human health in a Nigerian city-scale. The study confirmed that a substantial amount of outdoor air pollution contributed significantly to respiratory indicators (cough, phlegm, wheeze, and breathlessness) from the interviewed respondents. This relationship advocates the use of AirQ+ software and ATS questionnaire for estimating the incidence of respiratory symptoms, as they are effective tools when assessing the liability of respiratory symptoms in any polluted city. The results of this study indicates that there is a relationship between the observed criteria-pollutants, $\left(\mathrm{CO}, \mathrm{SO}_{2}, \mathrm{PM}_{2.5}\right.$, and $\left.\mathrm{PM}_{10}\right)$ and respiratory well-being of the study population in Zaria metropolis, Nigeria.
The study had five key strengths: (1) it revealed a metropolitan city air pollution level, high enough to be ranked amongst the WHO polluted cities; (2) the sources of respiratory related data obtained from the five major health facilities within the study area, ensured their authenticity and dependability; (3) two certified respiratory epidemiological indicators (ATS-DLD-78A questionnaire and the WHO AirQ+ software model) were adopted to examine the health effects of observed criteria pollutants; (4) the suspended particles $\left(\mathrm{PM}_{2.5}\right)$ had the most influence on the study population respiratory health, which is harmonious with other findings on this subject; and (5) our findings conclude that the respiratory symptoms investigated in this study are hypothetically associated with outdoor air pollutants measured using the MSA Altair $5 \times$ gas monitor and CW-HAT200 particulate counter.

We do recognize the following limitations in our study: (1) because the only two population censuses conducted in Nigeria were in 1991 and 2006, this study was constrained to adopt population estimates; (2) the RR coefficients adopted might have underestimated the extent of the attributable cases. However, we are confident that our results offer vital information on which Nigeria's policy makers can base its public health strategies and interventions; and (3) the unavoidable time variation in collecting pollution samples may 
have introduced marginal errors, we believe however, like similar studies in this field, that these errors are not significant enough to alter the findings of this study.

\section{ACKNOWLEDGEMENT}

This study is supported by the University of Pretoria postgraduate bursary and Ahmadu Bello University, Zaria NEEDS intervention grant to the first author. We acknowledge Tukur Dahiru for his support. We also appreciate health officers of the medical facilities that assisted in the respiratory health data acquisition. We are grateful to the anonymous reviewers for their efforts.

\section{CONFLICTS OF INTEREST}

The authors have no conflicts of interest to declare.

\section{REFERENCES}

[1] Gong X, Zhan FB, Brender JD, Langlois PH, Lin Y. Validity of the emission weighted proximity model in estimating air pollution exposure intensities in large geographic areas. Sci Total Environ 2016;563-564;478-85.

[2] Marais EA, Jacob DJ, Wecht K, Lerot C, Zhang L, Yu K, et al. Anthropogenic emissions in Nigeria and implications for atmospheric ozone pollution: a view from space. Atmos Environ 2014;99;32-40.

[3] Dash I. Space-time observations for city level air quality modelling and mapping. MSc Thesis, University of Twente, The Netherlands. 2016.

[4] Mehta S, Shin H, Burnett R, North T, Cohen AJ. Ambient particulate air pollution and acute lower respiratory infections: a systematic review and implications for estimating the global burden of disease. Air Qual Atmos Health 2013;6;69-83.

[5] Krupnick AJ. Challenges to managing air pollution. J Toxicol Environ Health 2008;71;13-23.

[6] Evans J, van Donkelaar A, Martin RV, Burnett R, Rainham DG, Birkett NJ, et al. Estimates of global mortality attributable to particulate air pollution using satellite imagery. Environ Res 2013;120;33-42.

[7] Miranda AI, Ferreira J, Silveira C, Relvas H, Duque L, Roebeling P, et al. A cost-efficiency and health benefit approach to improve urban air quality. Sci Total Environ 2016;569-570;342-51.

[8] Svendsen ER, Gonzales M, Mukerjee S, Smith L, Ross M, Walsh $\mathrm{D}$, et al. GIS-modeled indicators of traffic-related air pollutants and adverse pulmonary health among children in El Paso, Texas. Am J Epidemiol 2012;176(Suppl 7);S131-41.

[9] Ana GR, Odeshi TA, Sridhar MK, Ige MO. Outdoor respirable particulate matter and the lung function status of residents of selected communities in Ibadan, Nigeria. Perspect Public Health 2014;134;169-75.

[10] Obaseki DO, Adeniyi B, Jumbo J, Oyewo A, Irabor I, Erhabor GE. Respiratory symptom, lung function, and exhaled carbon monoxide among a sample of traffic workers in Lagos, Nigeria: a pilot survey. Niger Med J 2014;55;306-9.

[11] WHO (World Health Organization), Global urban ambient air pollution database update, 2016. Available at: http://www.who.
int/phe/health_topics/outdoorair/databases/WHO_AAP_database_May2016_v3web.xlsx?ua=1 [Date accessed: February 16, 2017].

[12] Thiering E, Heinrich J. Epidemiology of air pollution and diabetes. Trends Endocrin Metab 2015;26;384-94.

[13] Maheswaran R. Air pollution and stroke-an overview of the evidence base. Spat Spatiotemporal Epidemiol 2016;18;74-81.

[14] Checa Vizcaíno MA, González-Comadran M, Jacquemin B. Outdoor air pollution and human infertility: a systematic review. Fertil Steril 2016;106;897-904.e1.

[15] Oltra V, Saint Jean M. Variety of technological trajectories in low emission vehicles (LEVs): a patent data analysis. J Clean Prod 2009;17;201-13.

[16] Plaia A, Ruggieri M. Air quality indices: a review. Rev Environ Sci Biotechnol 2010;10;165-79.

[17] Wolff H. Keep your clunker in the suburb: low-emission zones and adoption of green vehicles. Econ J 2014;124;F481-F512.

[18] Abbasi IN, Ahsan A, Nafees AA. Correlation of respiratory symptoms and spirometric lung patterns in a rural community setting, Sindh, Pakistan: a cross sectional survey. BMC Pulm Med $2012 ; 12 ; 81$.

[19] Adams MD, Kanaroglou PS. Mapping real-time air pollution health risk for environmental management: Combining mobile and stationary air pollution monitoring with neural network models. J Environ Manage 2016;168;133-41.

[20] Oluwole O, Arinola GO, Huo D, Olopade CO. Household biomass fuel use, asthma symptoms severity, and asthma underdiagnosis in rural schoolchildren in Nigeria: a cross-sectional observational study. BMC Pulm Med 2017;17;3.

[21] Sarnat JA, Golan R, Greenwald R, Raysoni AU, Kewada P, Winquist A, et al. Exposure to traffic pollution, acute inflammation, and autonomic response in a panel of car commuters. Environ Res 2014;133;66-76.

[22] Peters A, von Klot S, Mittleman MA, Meisinger C, Hörmann A, Kuch B, et al. Triggering of acute myocardial infarction by different means of transportation. Eur J Prev Cardiol 2013;20;750-58.

[23] Patton AP, Laumbach R, Ohman-Strickland P, Black K, Alimokhtari S, Lioy PJ, et al. Scripted drives: a robust protocol for generating exposures to traffic-related air pollution. Atmos Environ 2016;143;290-99.

[24] NPC (National Population Commission), Population distribution by sex, state, LGA, senatorial district, 2006 population and housing census, 2010. Available at: http://www.population.gov.ng/ images/NPCNEW/Pr\%20Vol\%203\%20Pop\%20by\%20State\%20 \&\%20Senatorial\%20District.zip [Date accessed: December 15, 2016].

[25] Moltchanov S, Levy I, Etzion Y, Lerner U, Broday DM, Fishbain B. On the feasibility of measuring urban air pollution by wireless distributed sensor networks. Sci Total Environ 2015;502;537-47.

[26] Deary ME, Bainbridge SJ, Kerr A, McAllister A, Shrimpton T. Practicalities of mapping $\mathrm{PM}_{10}$ and $\mathrm{PM}_{2.5}$ concentrations on city-wide scales using a portable particulate monitor. Air Qual Atmos Health 2016;9;923-30.

[27] Thompson JE. Crowd-sourced air quality studies: a review of the literature and portable sensors. Trends Environ Anal Chem 2016;11;23-34.

[28] Efe SI, Efe AT. Spatial distribution of particulate matter $\left(\mathrm{PM}_{10}\right)$ in Warri metropolis, Nigeria. Environmentalist 2008;28; 385-94. 
[29] Bell ML, Davis DL. Reassessment of the lethal London fog of 1952: Novel indicators of acute and chronic consequences of acute exposure to air pollution. Environ Health Perspect 2001;109(Suppl 3);389-94.

[30] Nayeb Yazdi M, Delavarrafiee M, Arhami M. Evaluating near highway air pollutant levels and estimating emission factors: case study of Tehran, Iran. Sci Total Environ 2015;538;375-84.

[31] Fattore E, Paiano V, Borgini A, Tittarelli A, Bertoldi M, Crosignani $\mathrm{P}$, et al. Human health risk in relation to air quality in two municipalities in an industrialized area of Northern Italy. Environ Res 2011;111;1321-27.

[32] Nagpure AS, Gurjar BR, Martel Jc. Human health risks in national capital territory of Delhi due to air Pollution. Atmos Pollut Res 2014;5;371-80.

[33] Miri M, Derakhshan Z, Allahabadi A, Ahmadi E, Oliveri Conti G, Ferrante M, et al. Mortality and morbidity due to exposure to outdoor air pollution in Mashhad metropolis, Iran. The AirQ model approach. Environ Res 2016;151;451-57.

[34] Khaniabadi YO, Hopke PK, Goudarzi G, Daryanoosh SM, Jourvand M, Basiri H. Cardiopulmonary mortality and COPD attributed to ambient ozone. Environ Res 2017;152;336-41.

[35] Wang S, Feng X, Zeng X, Ma Y, Shang K. A study on variations of concentrations of particulate matter with different sizes in Lanzhou. China. Atmos Environ 2009;43;2823-28.

[36] Procházka B, Kynčl J. Estimating the baseline and threshold for the incidence of diseases with seasonal and long-term trends. Cent Eur J Public Health 2015;23;352-59.

[37] Ferris BG. Epidemiology standardization project (American Thoracic Society). Am Rev Respir Dis 1978;118;1-120.

[38] Albers PN, Wright CY, Voyi KV, Mathee A. Household fuel use and child respiratory ill health in two towns in Mpumalanga, South Africa: research. S Afr Med J 2015;105;573-77.

[39] Goldberg MS, Wheeler AJ, Burnett RT, Mayo NE, Valois MF, Brophy JM, et al. Physiological and perceived health effects from daily changes in air pollution and weather among persons with heart failure: a panel study. J Expo Sci Environ Epidemiol 2015:25;187-99.

[40] Schultz ES, Hallberg J, Bellander T, Bergström A, Bottai M, Chiesa F, et al. Early-life exposure to traffic-related air pollution and lung function in adolescence. Am J Respir Crit Care Med 2016;193;171-77.

[41] Brown J, Roy A, Harris R, Filson S, Johnson M, Abubakar I, et al. Respiratory symptoms in people living with HIV and the effect of antiretroviral therapy: A systematic review and meta-analysis. Thorax 2017;72;355-66.

[42] Krejcie RV, Morgan DW. Determining sample size for research activities. Educ Psychol Meas 1970;30;607-10.

[43] Sobrino JA, Jiménez-Muñoz JC, Paolini L. Land surface temperature retrieval from LANDSAT TM 5. Remote Sens Environ 2004;90;434-40.

[44] Xu D, Guo X. Compare NDVI extracted from Landsat 8 imagery with that from Landsat 7 imagery. Am J Remote Sens 2014;2;10-14.

[45] FEPA (Federal Environmental Protection Agency), Nationale Environmental (Effluent Limitations) Regulations. 1999. Available at: http://www.placng.org/new/laws/F10.pdf [Date accessed: September 8, 2016].

[46] WHO (World Health Organization), AirQ+: software tool for health risk assessment of air pollution. 2017. Available at: http:// www.euro.who.int/en/health-topics/environment-and-health/airquality/activities/airq-software-tool-for-health-risk-assessment-ofair-pollution [Date accessed: February 18, 2017].

[47] Halonen JI, Lanki T, Yli-Tuomi T, Tiittanen P, Kulmala M, Pekkanen J. Particulate air pollution and acute cardiorespiratory hospital admissions and mortality among the elderly. Epidemiology 2009;20;143-53.

[48] Ren M, Li N, Wang Z, Liu Y, Chen X, Chu Y, et al. The shortterm effects of air pollutants on respiratory disease mortality in Wuhan, China: Comparison of time-series and case-crossover analyses. Sci Rep 2017;7;40482. 